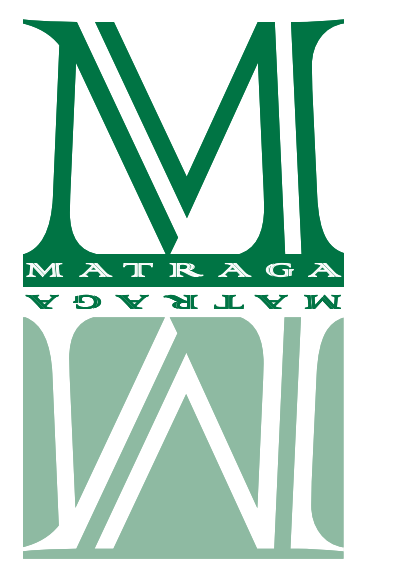

\title{
Inglês à mão: prática online de língua inglesa em tempos de distanciamento social
}

\author{
Marina Borges Muriana \\ Pontifícia Universidade Católica de São Paulo (PUC-SP) \\ https://orcid.org/0000-0002-9997-5582 \\ Solange Lopes Vinagre Costa \\ Pontifícia Universidade Católica de São Paulo (PUC-SP) \\ https://orcid.org/0000-0002-2659-8720
}

\section{RESUMO}

A pandemia do COVID-19 acentuou a urgência, já observada no contexto escolar presencial, do desenvolvimento de atividades e práticas docentes que possam abarcar estratégias de ensino-aprendizagem profícuas para um ambiente educacional exclusivamente virtual. Evidenciou também a importância de que as práticas de ensino reflitam as necessidades da contemporaneidade para a construção de um conhecimento in vivo (NICOLESCU, 2013), que é fluido, adaptável, em movimento. Trouxe, ainda, a necessidade de tratarmos aspectos da vida muitas vezes apartados do ambiente educacional, como a incerteza e a imprevisibilidade (MORIN, 2015). Nesse contexto, desenvolvemos a pesquisa apresentada neste artigo, a qual interpretamos a partir da abordagem metodológica hermenêutico-fenomenológica complexa (FREIRE, 2017). Articulando elementos da aprendizagem móvel (SACCOL et al., 2011) aos construtos da complexidade (MORIN, 2015) e da transdisciplinaridade (NICOLESCU, 2013), foi desenvolvida a situação de ensino-aprendizagem de inglês objeto desta pesquisa. Realizada no ambiente virtual do WhatsApp, contou com a participação de sete alunos adultos com níveis de proficiência diferentes durante duas semanas.

PALAVRAS-CHAVE: Transdisciplinaridade; Complexidade; Ensino-aprendizagem de inglês; Aprendizagem móvel

\section{English Language at Hand: Online english practice in times of social distancing}

\section{ABSTRACT}

The COVID-19 pandemic has emphasized the urgency, which could already be found in face-to-face school settings, for the development of teaching activities and practices with fruitful teaching-learning strategies for a new, exclusively virtual educational environment. It has also highlighted the importance that teaching practices reflect the needs of contemporaneity for an in vivo knowledge construction (NICOLESCU, 2013), which is fluid, adaptable, ever-changing. In addition, it has brought the need for teaching practices to deal with aspects of life that are sometimes excluded from the educational environment, such as uncertainty and unpredictability (MORIN, 2015). Taking such context into account, we carried out the research presented herein, which was interpreted in light of the complex hermeneutical-phenomenological approach (FREIRE, 2017). The teachinglearning experience that is the object of this research was developed by articulating elements of m-learning (SACCOL et al., 2011), complexity (MORIN, 2015), and transdisciplinarity (NICOLESCU, 2013). It was carried out for two weeks on the virtual environment of WhatsApp with seven adult learners of different proficiency levels.

KEYWORDS: Transdisciplinarity; Complexity; English language teaching-learning; M-learning 


\section{Pandemia e ensino-aprendizagem de língua inglesa}

O mundo experimentava, no início de 2020, ameaças como o aquecimento global, a fome, conflitos e guerras locais, a falta de acesso à educação de qualidade, entre tantas outras, quando foi surpreendido por um novo evento que exigiu seu enfrentamento imediato: a pandemia da COVID-19. Esse cenário gerou uma "megacrise feita da combinação de crises políticas, econômicas, sociais, ecológicas, nacionais, planetárias" (MORIN, 2020, p. 19) e exigiu mudanças na forma como agimos, socializamos e compreendemos o mundo.

No âmbito educacional, a necessidade de distanciamento social e de fechamento das escolas exigiu o súbito deslocamento das aulas para o ambiente remoto, demandando de professores e alunos adaptabilidade, flexibilidade e criatividade. Aos já existentes obstáculos enfrentados por professores e alunos de países de terceiro mundo, tais como a evasão escolar, a desmotivação e a falta de recursos, somaram-se novos entraves, como a dificuldade de acesso a recursos tecnológicos e a redes de $\mathrm{Wi}-\mathrm{Fi}$, o ambiente inadequado para estudos em lares com muitos moradores, a perda de empregos e outras fontes de renda, entre outras adversidades.

Assim como a vida, as crises geradas pela pandemia do coronavírus "se sustentam mutuamente com componentes, interações e indeterminações múltiplas e interligadas, ou seja, complexas, no sentido original da palavra complexus, 'o que é tecido junto"' (MORIN, 2020, p. 20). Por essa razão, pareceu relevante, na busca por soluções criativas para questões de ensino-aprendizagem de língua inglesa em momentos de distanciamento social, olhar para a complexidade (MORIN, 2015) e para a transdisciplinaridade (MORIN, 2014; NICOLESCU, 2013) como fontes de inspiração para repensar a ação docente.

Inseridas no contexto sócio-histórico da pandemia aqui descrito, seguimos nosso interesse como pesquisadoras em Linguística Aplicada e Estudos da Linguagem, nossa vontade de oferecer alternativas de aprendizagem reconfortantes a alguns de nossos alunos, e aproveitamos a facilidade, em nosso microcontexto, de reunir pessoas com os mesmos interesses no ambiente virtual para construir nosso projeto. Iniciamos uma pesquisa com o objetivo de revelar a percepção de aprendizes de língua inglesa sobre sua vivência em uma situação de ensino-aprendizagem na qual pudessem expressar, em inglês e em ambiente virtual, questões relacionadas à sua vida de maneira contextualizada, imprevisível e genuína. Utilizamos a abordagem hermenêutico-fenomenológica complexa (FREIRE, 2017) como fundamentação metodológica para a interpretação da pesquisa, a fim de descrever e interpretar o fenômeno "vivência em uma situação de ensino-aprendizagem online complexa e transdisciplinar". Recorremos também aos construtos da aprendizagem móvel, ou m-learning (SACCOL et al., 2011), da complexidade (MORIN, 2015) e da transdisciplinaridade (MORIN, 2014; NICOLESCU, 2013) como fundamentação teórica. Como pesquisa de campo para esse estudo, desenvolvemos uma situação de ensino-aprendizagem de inglês para promover a prática do idioma em uma interação no ambiente virtual do Whats $A p p^{1}$

\footnotetext{
1 WhatsApp é um aplicativo para troca de mensagens instantâneas que permite 0 envio de áudio, texto, vídeos e links, utilizado no cotidiano das pessoas e no mundo dos negócios.
} 
por um período de duas semanas e com a participação de sete alunos adultos de níveis de proficiência diferentes.

Após essas considerações iniciais, este artigo conta com quatro outras seções: a seção 2 traz considerações sobre aprendizagem móvel (SACCOL et al., 2011); a seção 3 apresenta os principais construtos da complexidade (MORIN, 2015) e da transdisciplinaridade (MORIN, 2014; NICOLESCU, 2013); a seção 4 descreve o contexto da situação de ensino-aprendizagem, seus participantes e algumas das atividades que a constituíram; a seção 5 apresenta a abordagem hermenêutico-fenomenológica complexa (FREIRE, 2017) e nossa interpretação, tecida a partir dos relatos dos alunos sobre sua participação e sobre as atividades.

\section{Aprendizagem móvel}

O uso da tecnologia digital na educação, mais especificamente no ensino-aprendizagem de língua inglesa, vem crescendo desde sua introdução na década de 1960. Embora muitas vezes observemos seu uso meramente na transposição de práticas tradicionais para o ambiente digital, a tecnologia tem, entre outros potenciais, o de permitir maior acesso a recursos que auxiliem na construção de conhecimento pertinente, que é aquele "capaz de situar qualquer informação em seu contexto" (MORIN, 2003, p. 15). O crescimento da aquisição de smartphones e do acesso à internet tem ampliado tais oportunidades, estando, cada vez mais, à mão de pessoas com desejo de se informar e aprender. Para Santaella (2010, p. 19), "acesso é o traço mais marcante do espaço virtual", marca constitutiva do advento da internet. Sendo assim, ao se pensar em práticas e atividades docentes, o acesso virtual pode expandir as propostas de ensino-aprendizagem de forma espacial, na própria rede, ou pedagógica e temporal, no deslocamento dos alunos e na disponibilidade para estudo.

Embora não represente necessariamente uma inovação, uma vez que sempre se buscou o uso de recursos, como livros e computadores para potencializar a aprendizagem (SACCOL et al., 2011, p. 17), o m-learning, pode proporcionar aos estudantes mais autonomia - lugar e tempo, por exemplo - na aprendizagem, acesso rápido a informações, entre outros benefícios (idem, p. 34-35). Compreende-se, portanto, que:

O m-learning (aprendizagem móvel ou com mobilidade) se refere a processos de aprendizagem apoiados pelo uso de tecnologias da informação ou comunicação móveis e sem fio, cuja característica fundamental é a mobilidade dos aprendizes, que podem estar distantes uns dos outros e também de espaços formais da educação, tais como salas de aula, salas de formação, capacitação e treinamento ou local de trabalho (SACCOL et al., 2011, p. 25).

Além do acesso a dispositivos móveis e redes de Wi-Fi, as iniciativas com aprendizagem móvel precisam considerar outros elementos contextuais dos aprendizes, que devem ser relevantes para a construção de conhecimento e podem variar de acordo com a situação e os sujeitos, bem como a mediação pedagógica, tanto de conteúdo quanto de contexto (SACCOL et al., 2011, p. 91).

O distanciamento social recomendado pelas autoridades de saúde para o enfrentamento da pandemia da COVID-19 parece ter intensificado a já crescente opção pela interação virtual. 
Mesmo antes da pandemia, o crescimento do acesso à internet fez surgir "novos padrões de interação social" (CASTELLS, 2003, p. 98) e a possibilidade da formação de uma sociedade de rede (idem, p. 111). Apesar das críticas sobre as possíveis consequências negativas do uso da internet, tais como "o colapso da comunicação social e da vida familiar" (idem, p. 98), Castells (2003, p. 102) apresenta pesquisas que demonstram seus efeitos positivos, como maior acesso à informação e ampliação do contato com amigos.

A demanda educacional contemporânea parece também estar atrelada à resolução de conflitos educacionais que persistem e se evidenciam, não somente no contexto presencial, mas também no digital. Tais conflitos advêm de uma "inteligência cega", já apontada por Morin (2015, p. 12), fruto de uma visão mutiladora e unidimensional do conhecimento, que "é cada vez menos feito para ser refletido e discutido pelas mentes humanas". O conhecimento, para o autor, muitas vezes advém de um paradigma da simplificação, marcado pela abstração e pela redução, que, apesar de ter permitido os maiores avanços científicos da história, originou também um pensamento disjuntivo, incapaz de religar as partes. No contexto educacional, isso se reflete na incapacidade de enxergarmos a articulação das disciplinas e saberes entre si e com a vida fora da escola, por exemplo. Essa simplificação do conhecimento no contexto presencial acabou sendo transferida para o ensino remoto, tanto em relação às práticas educacionais, quanto ao pensamento que as constrói.

Outro desafio educacional da atualidade parece ser o de encontrar maneiras que possibilitem acesso à internet com a mobilidade proporcionada pelo uso de smartphones por meio de metodologias que contribuam para a construção de conhecimento pertinente. Como salienta Castells (2003, p. 227), "antes de começarmos a mudar a tecnologia, a reconstruir as escolas, a reciclar os professores, precisamos de uma pedagogia baseada na interatividade, na personalização e no desenvolvimento da capacidade autônoma de aprender a pensar". Santaella (2010) evidencia o surgimento de uma nova lógica advinda da comunicação via digital e aponta para uma "cultura da mobilidade". Por isso, a construção de uma pedagogia da interatividade, sugerida por Castells, precisa contemplar a nova lógica ressaltada pela autora, a fim de construir novos espaços de ensino-aprendizagem.

Ainda do ponto de vista pedagógico, Saccol et al. (2011, p. 95-96) enfatizam a importância de que, no desenvolvimento de situações de ensino-aprendizagem móveis, leve-se em conta a coautoria dos alunos, uma vez que, no "m-learning [...], todos são pesquisadores, aprendizes e, também, mediadores pedagógicos, em contextos de aprendizagem que incluem diferentes metodologias problematizadoras [...], as quais podem ser propostas por qualquer um dos sujeitos". Enfatizam também a necessidade de que o planejamento das situações de ensino-aprendizagem móveis seja aberto e "que se adapte e respeite fundamentalmente os diferentes contextos de aprendizagem dos sujeitos envolvidos nesse processo, reorganizando-se sistemicamente a partir da própria dinâmica de desenvolvimento" (idem).

Considerando esses desafios e necessidades pedagógicas, apresentamos a seguir alguns construtos da complexidade e da transdisciplinaridade fundamentais para criarmos uma rede de aprendizagem e uma situação de ensino-aprendizagem de inglês via WhatsApp, por nós mediada, descrita adiante. 


\section{Complexidade e transdisciplinaridade}

A tessitura das definições de complexidade e transdisciplinaridade se faz em um terreno movente, no qual tais conceitos se mesclam dificultando a visualização de suas fronteiras. Por isso, é possível entender ambas como partes integrantes uma da outra; elas são todo e parte ao mesmo tempo, como um holograma, em que cada parte carrega o todo em si. Morin (2014) concebe a transdisciplinaridade como sendo um operador epistemológico do pensamento complexo. Por sua vez, Nicolescu (2013) entende a complexidade como uma característica da transdisciplinaridade. Assim, uma prática transdisciplinar é sempre uma prática complexa e vice-versa.

"A palavra método significa caminhada. É preciso agora aceitar caminhar sem um caminho, fazer o caminho enquanto se caminha", ressalta Morin (2016, p. 36) ao questionar a linearidade que constitui o pensamento científico e as epistemologias que constroem conhecimento e se constroem nas sociedades contemporâneas. A quebra da linearidade defendida por Morin pode ser observada tanto em acontecimentos cotidianos em nível local como naqueles em nível mundial, como a pandemia. Tal contexto, por exemplo, exige que tracemos novos caminhos ao longo do próprio caminho em si. Para o filósofo (MORIN, idem), o método se constrói durante a pesquisa, de maneira circular. Esse olhar pode nos conduzir a uma perspectiva educacional mais receptiva às incertezas e imprevisibilidades inerentes à vida, buscando caminhos de ensino-aprendizagem capazes de lidar com aspectos muitas vezes ignorados pelo paradigma científico tradicional. Este, baseado na análise, proporciona uma perspectiva educacional de fragmentação, em que subjaz a compartimentalização de saberes. Em contrapartida, uma visão educacional complexa e, por sua vez, transdisciplinar, entende que:

\footnotetext{
Na natureza, tudo é cíclico, assim, cabe refletir que o movimento natural de entropia no universo pode gerar a crise e o caos, mas permite rever, rediscutir e construir novas possibilidades. A nova reorganização precisa restituir ao homem e, por extensão, à natureza, o que foi perdido com a proposição do pensar tradicional, do capitalismo exacerbado e mais recentemente, da globalização desenfreada e descomedida (BEHRENS; OLIARI, 2007, p. 65).
}

Tendo por base o exposto pelas autoras, uma perspectiva educacional complexa enfatiza a circularidade dos fenômenos presentes na vida e na natureza, compreendendo que a relação entre causa e efeito não é linear, mas sim circular. Dessa forma, uma proposta de ensino-aprendizagem complexa e transdisciplinar pretende-se fluida, na qual a construção dos saberes leva em conta as incertezas e imprevisibilidades que permeiam a vida dos indivíduos envolvidos no processo, o contexto em que estão inseridos, os docentes, os conteúdos e recursos de aprendizagem disponíveis, entre outros. Além disso, compreender as relações dialógicas evidenciadas pela complexidade pode ser reconfortante, ao constatarmos que a dialógica é inerente à vida em suas mais variadas esferas, e ao mesmo tempo, angustiante, pois o pensamento linear, herança newtoniano-cartesiana, nem sempre nos permite enxergar a ordem presente no caos.

A pandemia da COVID-19 evidenciou aspectos já constituintes de uma sociedade em crise, marcados pela dialógica: a coexistência dos antagonismos morte e vida, falta de trabalho e 
excesso de trabalho, isolamento físico e aproximação virtual. Morin (2015) utiliza a ordem e a desordem que marcam a formação do universo para exemplificar a coexistência de tais características antagônicas:

O que digo a respeito da ordem e da desordem pode ser concebido em termos dialógicos. A ordem e a desordem são dois inimigos: um suprime o outro, mas ao mesmo tempo, em certos casos, eles colaboram e produzem organização e complexidade. O princípio dialógico nos permite manter a dualidade no seio da unidade. (MORIN, 2015, p. 74)

Tais aspectos enfatizam a complexidade que "está no coração da relação entre o simples e o complexo, porque tal relação é ao mesmo tempo antagônica e complementar" (MORIN, 2015, p. 103). Nesse cenário de ordem caótica, trazido pela pandemia, desenvolvemos a experiência de ensino-aprendizagem descrita a seguir.

\section{Entertainish}

No final de junho de 2020, o mundo já havia percebido que a pandemia e a necessidade de distanciamento social perdurariam mais do que o inicialmente previsto. Nesse contexto, observamos a necessidade de inovações para o contexto de aprendizagem formal que compreendessem as mudanças cognitivas trazidas por determinados recursos tecnológicos (SACCOL et al., 2011; SANTAELLA 2010; LEFFA 2016) e desenvolvemos uma proposta de ensino-aprendizagem de inglês para o ambiente virtual.

Sete de oito alunos convidados participaram, dois homens e cinco mulheres adultos, com idade entre 20 e 60 anos, e níveis de proficiência variando entre A1 e B2 ${ }^{2}$, todos residentes na região metropolitana de São Paulo. Eles demonstraram interesse por temas relativos a diferentes formas de entretenimento, conforme respostas ao questionário inicial, bem como disponibilidade de participar de uma situação de ensino-aprendizagem extraclasse gratuita, a qual visou promover a prática da língua via WhatsApp.

A escolha desse aplicativo se deveu à nossa percepção de sua frequente utilização pelos alunos em suas interações pessoais, bem como por acreditarmos que tal escolha pudesse proporcionar um ambiente informal de interação e propiciar uma prática mais autêntica de uso da língua para a temática escolhida. Além disso, buscamos lidar com necessidades metodológicas que são um desafio para a escola contemporânea, entendendo que "diferentes modos de aprender e de se relacionar com o conhecimento têm surgido a partir das redes sociais e das comunidades de prática. Com elas, emerge a necessidade de novos letramentos e de outras formas de construção de conhecimento" (GOMES, 2016, p. 87).

Dessa forma, propostas pedagógicas que incluam redes sociais, aplicativos de mensagens, entre outros ambientes virtuais são fundamentais para a construção de conhecimento necessária

\footnotetext{
${ }^{2}$ Classificação feita segundo o Quadro Europeu Comum de Referência para Línguas.
} 
para a vida na sociedade contemporânea. Consideramos, assim, o WhatsApp como um ambiente fértil para a construção de uma comunidade de prática pertinente.

A temática da situação de ensino-aprendizagem foi proposta a partir de nosso entendimento de que muitos de nossos alunos, submetidos ao isolamento social, buscaram preencher o tempo livre a fim de amenizar angústias causadas pelas notícias sobre a COVID-19 e suas consequências ao redor do mundo. Acreditamos, portanto, que uma das alternativas de uso desse tempo tanto pelos alunos quanto pelas professoras poderia ser assistindo a séries e filmes e ouvindo música, entre outras formas de distração, e praticando inglês. O ambiente virtual também nos pareceu propício para reunir pessoas com os mesmos interesses, já que o contexto de aprendizagem móvel pode favorecer "a formação de grupos conforme afinidades e/ou complementaridade de interesses e competências dos sujeitos" (SACCOL et al., 2011, p. 96). Considerando tais aspectos, propusemos o título da situação de ensino-aprendizagem e o nome do grupo no aplicativo: Entertainish (Entertainment \& English).

As atividades propostas nas duas semanas de interação buscaram ecologizar (MORIN, 2000) o ensino-aprendizagem de inglês, considerando elementos da formação cultural e social dos alunos ao identificar seu interesse por atividades de entretenimento. Para isso, propusemos sete tasks, nas quais os participantes expressaram e discutiram suas preferências e conhecimento sobre a temática, por meio de postagens de áudio, textos, imagens ou gifs. As atividades buscaram oferecer oportunidades para que os alunos trouxessem para o ambiente virtual questões relacionadas a sua vida, permitindo que interagissem em língua inglesa de forma genuína.

Embora propostas pelas professoras, as atividades buscaram refletir os interesses e necessidades dos alunos, bem como dar-lhes a oportunidade de colaborarem para sua idealização. Muitas partiram de suas respostas, buscando promover sua participação ativa também na construção das atividades, como coautores. Em uma das atividades, por exemplo, os alunos foram convidados a selecionar o trailer de um filme ou série que gostariam de recomendar, postar o link no WhatsApp e gravar um áudio em inglês dizendo por que estavam fazendo a recomendação. Todos os alunos também eram estimulados a comentar sobre as postagens dos colegas, fazer sugestões e interagir entre si, como mostra a Figura 1.

As atividades foram desenvolvidas de modo que o aluno pudesse interagir o mais naturalmente possível com outros falantes da língua inglesa. Entretanto, do ponto de vista de seu desenvolvimento, todas as atividades propostas visavam a construção de conhecimento, ou seja, vocabulário, estruturas da língua, ou o desenvolvimento de alguma habilidade a partir da língua em uso - compreensão leitora ou auditiva, produção escrita ou oral. Além de pesquisadoras e desenvolvedoras das atividades, entendemos que participamos da situação de ensino-aprendizagem, uma vez que respondíamos às atividades, ora para apresentar um modelo, ora para comentar, e aprendíamos junto com os alunos em uma parceria genuína.

A incerteza (MORIN, 2015, p. 35) e a imprevisibilidade (idem, p. 82) foram características da complexidade muito presentes durante todo o processo de interação, tanto na maneira como as atividades foram propostas, quanto nos caminhos que as respostas dos participantes percorreram. Um exemplo desses aspectos na fase de planejamento das atividades foi o convite para selecionar, em um site em língua inglesa com 50 opções para se distrair e se divertir de forma 
FIGURA 1: Mensagem no WhatsApp para Task

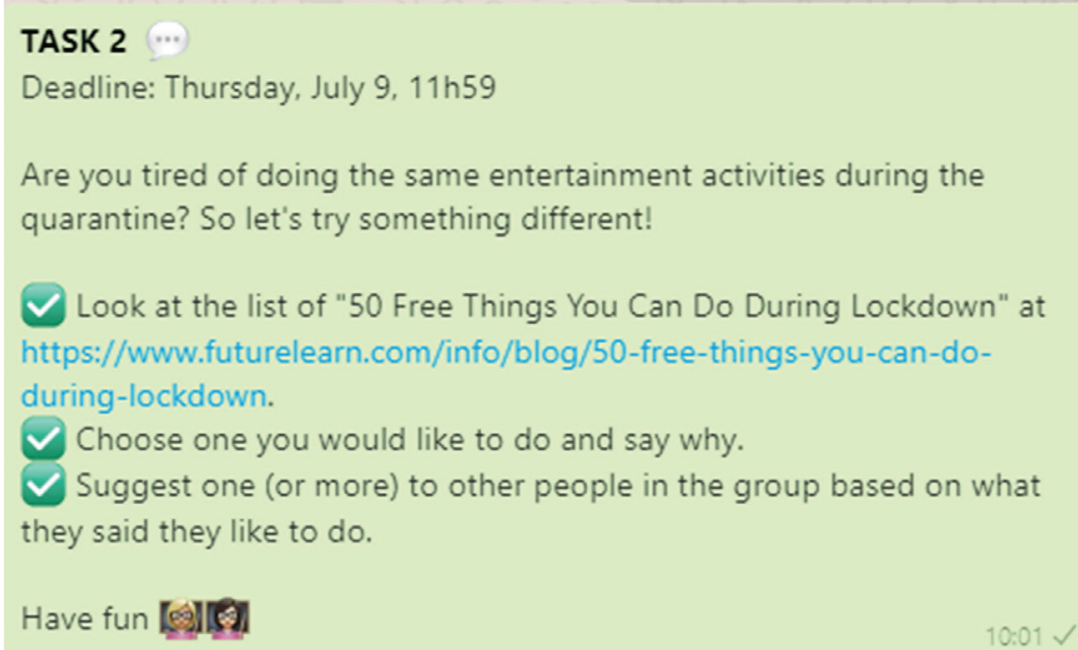

Fonte: captura de tela das autoras.

gratuita durante o isolamento social, uma sugestão que os agradasse e postar um comentário sobre ela (Figura 1). A impossibilidade de prever as escolhas dos alunos nos permitiu acolher a imprevisibilidade e a incerteza em nossa prática, visto que não haveria controle sobre as estruturas linguísticas a serem utilizadas pelos alunos, estando asseguradas pela perspectiva de que as línguas são vivas e fluidas, pois estão intrinsicamente conectadas ao pensamento humano. Metodologicamente, buscamos oferecer uma oportunidade de uso autêntico da língua, menos focado em classificações e regras gramaticais, por exemplo.

Ainda sobre a imprevisibilidade e a incerteza nos caminhos trilhados pelos participantes, podemos destacar também a atividade inicial, na qual os alunos teriam de se apresentar e falar sobre suas atividades favoritas de entretenimento via áudio. Uma aluna disse gostar de cuidar de suas plantas e, curiosamente, vários participantes compartilhavam do mesmo interesse. Espontaneamente, postaram fotos de suas plantas, fizeram comentários e mencionaram aprender sobre nomes de plantas, construções de saberes não previstas no planejamento da atividade. A oportunidade que essa atividade gerou para os alunos de decidirem seguir por caminhos não previstos mostra não somente que o planejamento dessa situação de ensino-aprendizagem foi aberto e flexível, mas também que os participantes se tornaram "corresponsáveis e coatores da produção coletiva de conhecimentos e auxiliando-se mutuamente nas produções individuais", duas características importantes para a aprendizagem móvel segundo Saccol et al. (2011, p. 96).

O exemplo exposto anteriormente também traz características da transdisciplinaridade, uma vez que ela lida com o conhecimento in vivo (NICOLESCU, 2013, p. 18). Dessa forma, os alunos trabalham em um movimento de coconstrução das atividades propostas, pois indiretamente praticaram e interferiram na prática de todo o grupo. Além disso, permitir que os alunos expressem suas opiniões e sentimentos é uma tentativa de "encontrar equilíbrio em nosso sistema educativo entre a inteligência analítica e o ser interior" (idem, tradução nossa), muitas vezes apagado das interações das aulas de línguas em detrimento de práticas analíticas, categorização, classificação e teorização sobre a língua estudada. 
Retomando a questão da coautoria dos alunos e do planejamento aberto, outra atividade exemplifica tais características. O planejamento inicial previa uma atividade na qual os alunos responderiam, em conjunto, a perguntas sobre filmes. Eram 20 perguntas e cada aluno deveria escolher uma e adicionar sua resposta no próprio ambiente do WhatsApp. Cada aluno, a seu tempo, deveria copiar a mensagem do colega anterior, adicionar uma resposta, e assim sucessivamente até que todas fossem respondidas e as respostas corretas pudessem ser confirmadas no site onde o quiz foi originalmente proposto. O sucesso dessa atividade pareceu-nos uma oportunidade de propormos uma atividade não prevista inicialmente: os alunos desenvolveriam seu próprio quiz. Foram, então, instruídos a criar uma pergunta sobre filmes ou séries, o que gerou certa dificuldade, de acordo com o relato de alguns alunos, pois, além de conceberem a ideia, tiveram que redigir a pergunta em inglês. Utilizando o Quizizz $z^{3}$, transpusemos para o ambiente online as 15 perguntas criadas pelo grupo, para as quais tivemos que pesquisar as respostas e pensar nas demais alternativas de escolha múltipla. A criação gerou o que chamamos de Bonus Task (Figura 2), onde os alunos deveriam responder ao quiz que haviam criado.

\section{FIGURA 2: Mensagem no WhatsApp para Bonus Task}

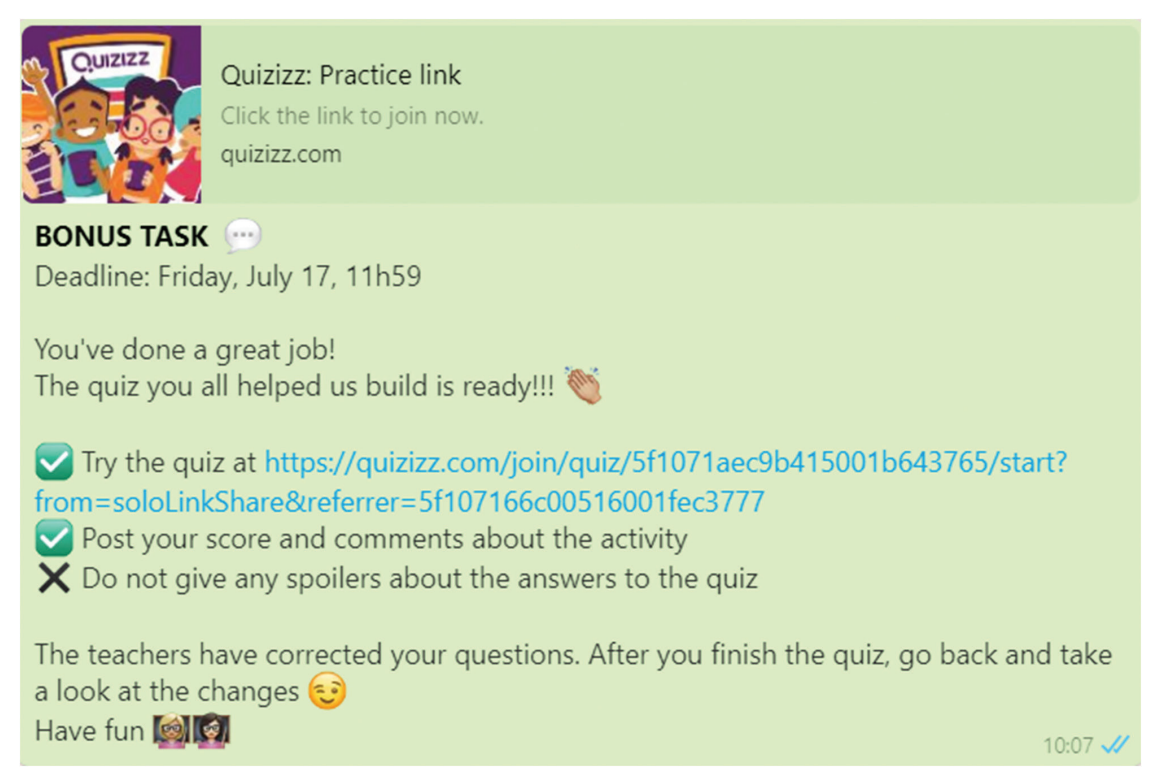

Fonte: captura de tela das autoras.

A intepretação das respostas dos alunos ao questionário final, apresentada a seguir, pode elucidar mais sobre o Entertainish.

\section{Abordagem metodológica e interpretação}

Compreendemos que a pesquisa científica tem uma limitação temporal - ao narrarmos um fenômeno pesquisado, ele próprio já se transformou - e que essa fluidez é também uma ca-

${ }_{3}$ Quizizz é um aplicativo gratuito para a criação de quizzes e enquetes. Disponível em < https://quizizz.com/join> 
racterística que se destaca na contemporaneidade. Assim, consideramos que uma abordagem metodológica qualitativa pode ser mais pertinente ao fenômeno que optamos por interpretar. Uma alternativa coerente com a nossa proposta é a abordagem hermenêutico-fenomenológica complexa (FREIRE, 2017), que propõe, por meio de um processo de mergulho interpretativo, a descoberta de temas que descrevam o fenômeno em foco. A abordagem parte, por isso, de registros escritos, que permitem revisitar os textos descritivos do fenômeno inúmeras vezes, até que o pesquisador chegue a um substantivo que, segundo Freire (2017, p. 178) "será a última redução possível, a unidade mais refinada e a que melhor expressa a ressignificação desejada”. Para a busca de tais temas, foram gerados sete textos, nos quais os participantes responderam às seguintes perguntas:

- Conte-nos suas impressões sobre a vivência no Entertainish.

- Como foi praticar inglês via WhatsApp?

- Conte-nos sobre o que você aprendeu.

A leitura do fenômeno a partir da interpretação das respostas evidenciou temas, subtemas e subsubtemas ${ }^{4}$. A teia de significações construída a partir das emergências indica que, na perspectiva dos alunos, a vivência no curso proposto permitiu a "Prática", a "Conversa" e a "Aprendizagem" de "inglês", o que já era esperado. Permitiu também uma "Prática" de "escrita", "fala" e "comunicação" de maneira descontraída e ágil. O subtema agilidade reforça a necessidade da percepção da ampliação do tempo no ambiente virtual. Saccol et al. (2011) consideram que

o tempo é uma questão crucial na atualidade; assim, saber 'aproveitar' o tempo que se tem, esteja ele vinculado ao contexto de deslocamento, à espera de um atendimento, a 'janelas' entre reuniões, viagens etc., representa uma vantagem para os sujeitos que desejam aprender. (SACCOL et al., 2011, p. 59)

O entendimento das vantagens percebidas pelos alunos em relação ao uso de seu tempo pode trazer diversas percepções metodológicas aos professores e designers de cursos. Do excerto "falamos sobre filmes e séries o que é algo que gosto muito, sendo assim, você aprende brincando (participante Arthur ${ }^{5}$ ), a emergência do subtema "descontração", apesar de não indicar uma urgência pedagógica, ou um desafio educativo a ser superado, apresentou-se como uma constatação exitosa para nós, uma vez que era um de nossos objetivos proporcionar uma vivência reconfortante para nossos alunos em tempos de pandemia.

Outro tema relevante foi "Troca", acompanhado dos subtemas "experiências" e "conhecimento", emergências dos excertos "achei muito interessante a troca de experiências e conhecimentos sobre filmes..." (participante Iná), e "é ótimo falar de assuntos que gostamos, trocar informações, ouvir opiniões" (participante Elis). Três dos alunos nomearam o aplicativo como uma "Ferramenta", entendendo-a como sendo de "aproximação", de "aprendizagem" e de "estudos". Essa

\footnotetext{
${ }^{4}$ Optamos por diferenciar os temas e subtemas identificando-os em itálico. Os temas aparecem com a inicial maiúscula.

${ }^{5}$ Nomes fictícios para manter o sigilo da pesquisa.
} 
constatação dos alunos é de extrema importância, uma vez que desperta neles a compreensão de que um recurso existente em seu cotidiano pode também promover aprendizagem, e contribuir para sanar um dos problemas do ensino de língua inglesa no Brasil apontado por Leffa (2016):

$\mathrm{Na}$ maioria das situações, como no caso da língua inglesa no Brasil, o aluno não tem com quem interagir, se considerarmos uma situação autêntica de comunicação. A interação fica na base do faz-de-conta: eu faço de conta que sou o recepcionista do hotel e você faz de conta que é o turista americano. (Leffa, 2016, p. 137)

O autor ressalta, ainda, que, apesar de termos acesso a situações autênticas de uso da língua, como a leitura de livros, a escuta de músicas e filmes, por exemplo, tais situações "são processos que ficam restritos à recepção da língua”, não permitindo que haja uma interação "com um interlocutor autêntico para a prática oral plena da língua estrangeira" (LEFFA, 2016, p. 140-141). Por isso, a emergência de tema e subtema "Troca" de "experiências" reforça o potencial do aplicativo WhatsApp de promover uma situação comunicativa autêntica, com interlocutores autênticos, que extrapole as situações de faz-de-conta mencionadas por Leffa. Além disso, a possibilidade de interação via mensagens de áudio se torna imprescindível para o desenvolvimento da oralidade em tal contexto, sendo um recurso que deve ser incluído e estudado mais amplamente do ponto de vista pedagógico.

Emergiram também, dos excertos sobre o uso do aplicativo, como por exemplo o da participante Iná, "prático e tranquilo. O formato utilizado permitiu que as tarefas fossem solicitadas de forma clara e objetiva, facilitando a execução", do participante Arthur "achei bem pessoal, diferente", e da participante Lisa "foi mais fácil que imaginava, a dinâmica ajudou (perguntas com prazos, áudios, vídeos)" os temas "Praticidade", "Facilidade" e "Personalização". Tais temas parecem estar relacionados ao aspecto da mobilidade trazida pelos smartphones, a qual, de acordo com Saccol et al. (2011, p. 66) "permite ao sujeito decidir quando, onde e de que forma ele vai se engajar em um processo de formação ou capacitação". Ao se adaptar ao tempo de cada um, o WhatsApp é um recurso bastante viável para a personalização da aprendizagem, ao mesmo tempo em que contribui para uma aprendizagem coletiva devido a interação que promove. É, por isso, um recurso em potencial para o desenvolvimento de propostas transdisciplinares, uma vez que uma das características fundamentais da transdisciplinaridade é a simultaneidade (NICOLESCU, 2013).

Em relação à aprendizagem, três dos sete alunos fizeram menção a aspectos estruturais da língua, mas somente um especificou-os; os outros quatro observaram questões mais relacionadas com as temáticas discutidas, relacionadas à sua rotina ou sua vida. A menção aos aspectos estruturais pode se dever ao fato de que, apesar de ocorrer em um ambiente não-formal de aprendizagem, a situação de ensino-aprendizagem foi proposta por professoras, e um dos objetivos claros era a prática da língua. Por isso, uma das expectativas implícitas era a aprendizagem das estruturas, mesmo não sendo de uma maneira normativa.

O tema "Aprendizagem", presente em todos os textos, acompanhado de seus subtemas "séries, filmes, plantas, palavras, expressões, frases, verbos, pronúncia, curiosidades, comunicação, interação, leitura, descontração e diversão", emergências de excertos como "novas palavras, expres- 
sões, frases, tempo verbal e pronúncia. Sem falar das dicas e curiosidades sobre filmes e outros assuntos comentados" (participante Iná), "formas mais fáceis de se comunicar e algumas regras de tempo (participante Isadora), "sugestões de series e filmes, bem como de plantas (participante Lisa), e "com toda sinceridade, li mais do q no semestre todo" (participante Elis), ilustra a percepção dos participantes do que foi tratado no curso. Tal percepção evidencia a articulação de elementos presentes em sua vida cotidiana a elementos de espaços formais de aprendizagem da língua. Essa articulação é importante em um ambiente não-formal de aprendizagem, pois promove uma nova forma de pensar os espaços educacionais sem rejeitar conteúdos que orientaram cognitivamente a construção de conhecimento até aqui, afinal, "a complexidade chegou a nós, nas ciências, pelo mesmo caminho que a tinha expulsado" (MORIN, 2015, p. 14). Por isso, uma aprendizagem de religação de saberes pode emergir também de vias tradicionais como as que orientaram o ensino de línguas ao longo da história, em que acabamos "transformando a língua em um objeto teórico de estudo, um conteúdo a ser discutido e explicado, como se faz com o ensino da física ou da matemática" (LEFFA, 2016, p. 139). É interessante, portanto, buscar um caminho que não rejeite totalmente os sucessos que nos trouxeram até aqui, mas reflita sobre as falhas e possibilidades de avançar conforme as mudanças do mundo.

\section{Reflexões finais}

A proposta aqui apresentada buscou contribuir com a construção de novos caminhos educacionais, sobretudo os que contemplem características evidenciadas por fenômenos inerentes à vida, como a pandemia da COVID-19. As incertezas e imprevisibilidades trazidas por tal cenário parecem romper com nossa falsa sensação de controle sobre a vida, fruto de uma lógica exclusivamente linear e que permeia a construção de conhecimento. Por isso, fundamentadas na premissa de que "a nova educação tem que inventar novos métodos de ensinar, fundados em novas lógicas” (NICOLESCU, 2013, p. 18, tradução nossa), buscamos sanar uma das necessidades do ensino de língua estrangeira, que é oferecer ambientes genuínos de prática da língua atrelados ao planejamento de situações de ensino-aprendizagem pensadas para eles. Além disso, propusemos alternativas para o pensamento metodológico do ensino de língua inglesa, considerando que "as redes digitais de relacionamento têm permitido e potencializado novas formas de ser e de estar no mundo, de ensinar e de aprender. Aprende-se em todos os lugares, e nesse sentido, podemos dizer que há uma escola fora da escola" (GOMES, 2016, p. 83).

Compreendemos também a necessidade de aprofundarmos nossa pesquisa para outros aspectos pedagógicos, como a questão da avaliação, por exemplo. Apesar de termos oferecido feedback individual aos participantes ao final da vivência, tecendo comentários positivos sobre sua participação no desenvolvimento da situação de ensino-aprendizagem, ativemo-nos prioritariamente à dimensão da correção, ou seja, apontamos palavras ou estruturas que foram utilizadas incorretamente de acordo com as regras gramaticais ou de pronúncia, e sugerimos opções adequadas à norma culta. Entretanto, posteriormente compreendemos que poderíamos ter, por exemplo, recorrido à autoavaliação, por exemplo. Ressaltamos a necessidade de buscarmos no- 
vas formas de pensar a avaliação, bem como suas deficiências e até mesmo sua imprescindibilidade. Na falta de recursos metodológicos para fazê-la, recorremos a um caminho familiar a nossa prática docente. Isso reforça a importância de compreendermos o mérito dos fundamentos científicos construídos até aqui.

Por fim, anuímos com a percepção de Morin (2020, p. 20) de que o "futuro imprevisível está em gestação hoje. Tomara que seja para a regeneração da política, para a proteção do planeta e para a humanização da sociedade: está na hora de mudar de Via”. Entendemos, assim, que nossa prática educativa, sobretudo durante períodos de adversidade e crises como a pandemia da COVID-19, possa gerar um futuro de regeneração, principalmente humana. Para isso, buscamos promover situações de ensino-aprendizagem mais condizentes com as necessidades geradas pelo contexto, em uma tentativa pedagógica mais acolhedora e humanizada. Esperamos que a pandemia possa ter possibilitado a professores e alunos encontrar novas alternativas para a construção de saberes em língua inglesa, e que tal conhecimento possa contribuir para a superação e/ou convivência mais harmônica frente às ameaças já existentes e as que surgirão após a pandemia.

\section{REFERÊNCIAS}

BEHRENS, Marilda Aparecida; OLIARI, Anadir Luiza Thomé. A evolução dos Paradigmas na Educação: do pensamento científico tradicional a complexidade. Curitiba: Revista Diálogo Educacional. v.7 n. 22, p. 53-66, set/dez 2007.

CASTELLS, Manuel. A galáxia da internet: reflexões sobre a internet, os negócios e a sociedade. Trad. Maria Luiza X. de A. Borges. Rio de Janeiro: Zahar, 2003.

FREIRE, Maximina Maria. Uma abordagem metodológica e uma teoria do conhecimento: relato de um encontro e a emergência de uma tessitura. In: FREIRE, Maximina Maria; BRAUER, Karin Claudia Nin; AGUILAR, Gabriel (Orgs.). Vias para a pesquisa: reflexões e mediações. São Paulo: Cruzeiro do Sul Educacional, Campus Virtual, p. 176-182, 2017.

GOMES, Luiz Fernando. Redes sociais e escola: o que temos de aprender? In: ARAÚJO, Júlio; LEFFA, Vilson (Orgs.). Redes sociais e ensino de línguas: o que temos de aprender? São Paulo: Parábola Editorial, p. 81-92, 2016.

LEFFA, Vilson. Redes sociais: ensinando línguas como antigamente. In: ARAÚJO, Júlio; LEFFA, Vilson (Orgs.). Redes sociais e ensino de línguas: o que temos de aprender? São Paulo: Parábola Editorial, p. 137$151,2016$.

MORIN, Edgar. Complexidade e Transdisciplinaridade: a reforma da universidade e do ensino fundamental. Natal: EDUFRN, 2000.

MORIN, Edgar. A cabeça bem-feita: repensar a reforma, reformar o pensamento. Trad. Eloá Jacobina. 8a ed. Rio de Janeiro: Bertrand Brasil, 2003.

MORIN, Edgar. Ciência com consciência. Trad. Maria D. Alexandre e Maria Alice Araripe de Sampaio Doria. Rio de Janeiro: Bertrand Brasil, 2014. 
MORIN, Edgar. Introdução ao pensamento complexo. Trad. Eliane Lisboa. 5ed. Porto Alegre: Sulina, 2015.

MORIN, Edgar. O Método 1: a natureza da natureza. Porto Alegre: Sulina; 2016.

MORIN, Edgar. É hora de mudarmos de via: as lições do coronavírus. Colaboração Sabah Abouessalam. Trad. Ivone C. Benedetti. Rio de Janeiro: Bertrand Brasil, 2020. Recurso digital.

NICOLESCU, Basarab. The need for transdisciplinarity in higher education in a globalized world. In: Transdisciplinary theory and practice. USA: Atlas Publishing, 2013.

SACOLL, Amarolinda, SCHLEMMER, Eliane, BARBOSA, Jorge. M-learning e U-learning: novas perspectivas da aprendizagem móvel e ubíqua. São Paulo: Pearson Prentice Hall, 2011.

SANTAELLA, Lucia. A aprendizagem ubíqua substitui a educação formal? 2010. Disponível em: <https:// revistas.pucsp.br/ReCET/article/download/3852/2515>. Acesso em: 21 dez. 2020. 